\title{
Engagement of employees in a research organisation: A relational perspective
}

\begin{tabular}{|c|c|}
\hline $\begin{array}{l}\text { Authors: } \\
\text { Doris Asiwe } \\
\text { Sebastiaan Ro } \\
\text { Lene Jorgense } \\
\text { Carin Hill }\end{array}$ & $\begin{array}{l}\text { thmann }{ }^{1} \\
\text { n }^{2}\end{array}$ \\
\hline $\begin{array}{l}\text { Affiliations: } \\
{ }^{1} \text { Optentia Res } \\
\text { Area, North-V } \\
\text { South Africa }\end{array}$ & $\begin{array}{l}\text { earch Focus } \\
\text { Vest University, }\end{array}$ \\
\hline $\begin{array}{l}{ }^{2} \text { WorkWell Re } \\
\text { School of Hun } \\
\text { Science, Nort } \\
\text { University, So }\end{array}$ & $\begin{array}{l}\text { search Unit, } \\
\text { nan Resource } \\
\text { ר-West } \\
\text { uth Africa }\end{array}$ \\
\hline $\begin{array}{l}{ }^{3} \text { Department } \\
\text { Psychology ar } \\
\text { Management } \\
\text { Johannesburg }\end{array}$ & $\begin{array}{l}\text { of Industrial } \\
\text { d People } \\
\text { University of } \\
\text { South Africa }\end{array}$ \\
\hline $\begin{array}{l}\text { Correspondin } \\
\text { Sebastiaan Ro } \\
\text { ian@ianrothn }\end{array}$ & $\begin{array}{l}\text { g author: } \\
\text { thmann, } \\
\text { lann.com }\end{array}$ \\
\hline $\begin{array}{l}\text { Dates: } \\
\text { Received: } 12 . \\
\text { Accepted: } 17 \\
\text { Published: } 07\end{array}$ & $\begin{array}{l}\text { an. } 2016 \\
\text { Feb. } 2017 \\
\text { Apr. } 2017\end{array}$ \\
\hline $\begin{array}{l}\text { How to cite th } \\
\text { Asiwe, D., Rot } \\
\text { Jorgensen, L. } \\
\text { 'Engagement } \\
\text { a research org } \\
\text { relational pers } \\
\text { African Journo } \\
\text { and Managen } \\
20(1) \text {, a1534. } \\
\text { org/10.4102/s } \\
\text { v20i1.1534 }\end{array}$ & $\begin{array}{l}\text { is article: } \\
\text { hmann, S., } \\
\text { \& Hill, C., 2017, } \\
\text { of employees in } \\
\text { sanisation: A } \\
\text { pective', South } \\
\text { ll of Economic } \\
\text { nent Sciences } \\
\text { https://doi. } \\
\text { sajems. }\end{array}$ \\
\hline $\begin{array}{l}\text { Copyright: } \\
\text { (c) 2017. The } \\
\text { Licensee: AOS } \\
\text { is licensed un } \\
\text { Creative Comr } \\
\text { Attribution Lic }\end{array}$ & $\begin{array}{l}\text { uthors. } \\
\text { IS. This work } \\
\text { der the } \\
\text { nons } \\
\text { ense. }\end{array}$ \\
\hline Read online: & \\
\hline 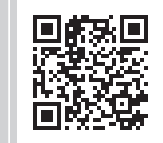 & $\begin{array}{l}\text { Scan this QR } \\
\text { code with your } \\
\text { smart phone or } \\
\text { mobile device } \\
\text { to read online. }\end{array}$ \\
\hline
\end{tabular}

Background: Increasing work engagement in a sustainable way remains a challenge despite years of research on the topic. Relationships at work are vital to foster engagement or disengagement. While the relational model by Kahn and Heaphy is conceptually appealing to explain work engagement, it lacks empirical support.

Aims: The aims of this study were to investigate the associations among relational factors, psychological conditions (psychological meaningfulness, availability and safety) and work engagement and to test a structural model of work engagement.

Setting: A total of 443 individuals in an agricultural research organisation participated in a cross-sectional study.

Methods: Four scales that measured relational factors, the Psychological Conditions Scale and the Work Engagement Scale were administered. Latent variable modelling was used to test the measurement and structural models.

Results: The results confirmed a structural model in which relational facets of job design contributed to psychological meaningfulness. Emotional exhaustion (inverse) and co-worker relationships contributed to psychological availability. Supervisor relationships contributed to psychological safety. Psychological meaningfulness and psychological availability contributed to work engagement, while emotional exhaustion contributed to disengagement.

Conclusion: The relational context is an important target for intervention to affect the psychological conditions which precede work engagement. To promote work engagement, it is vital to focus on psychological meaningfulness, psychological availability and emotional exhaustion.

\section{Introduction}

Work engagement is an important research theme for both practitioners and researchers because it correlates with many work participation outcomes (Bakker \& Leiter 2010). Increasing work engagement in a sustainable way remains a challenge despite years of research on the topic (Rothmann 2017). Research on engagement has often been done from the perspective of the Job Demands-Resources (JD-R) model (Bakker \& Demerouti 2007, 2008; Schaufeli \& Bakker 2004). In contrast, Kahn and Heaphy (2014) developed a relational model of work engagement. An advantage of the relational model (compared to the JD-R model) is that it includes psychological conditions as experienced by individuals as possible mediators between work engagement and its antecedents. Isolating the psychological conditions that mediate the relations between work engagement and its antecedents makes it possible to understand and manage the effects of such conditions.

Engagement reflects the simultaneous investment of cognitive, emotional and physical energies in such a way that one is actively and completely involved in the full performance of a role (Rich, Lepine \& Crawford 2010). Hence, engaged employees are physically involved in their tasks, cognitively alert and emotionally connected to others when performing their jobs. Engagement can be regarded as a psychological state (Rothbard \& Patil 2012), which implies that, depending on specific antecedents, it could vary over time. According to Saks, engagement involves being 'psychologically present when occupying and performing an organizational role' (2006:601). Similarly, Kahn (1990) conceptualised engagement as an extension of the self, through the psychological conditions of meaningfulness, safety and availability to a work role. These psychological conditions affect personal engagement and disengagement at work (Kahn 1990; Kahn \& Heaphy 2014). Psychological meaningfulness, safety and availability are embedded in the context of relationships at work. Therefore, relationships at work are vital to foster engagement or 
disengagement (Kahn \& Heaphy 2014). Work relationships affect people's experiences of the purposes of their work, heighten their sense of belonging and energise them. Individuals who feel emotionally exhausted might find it difficult to engage in work. Furthermore, individuals define the context in which they can feel safe or unsafe to express themselves and sustain or weaken limitations essential to sustain availability at work (Kahn \& Heaphy 2014).

Although the relational model of work engagement is conceptually appealing, it lacks empirical support. Utilising previous research of Kahn (1990), Rothmann and Welsh (2013) tested a model that did not focus exclusively on relational factors. They found that work role fit, job enrichment and the availability of resources affected work engagement indirectly via experiences of psychological meaningfulness, while the availability of resources and coworker relationships affected work engagement indirectly through psychological availability. Janik and Rothmann (2016) focused on the effects of selected relational factors (i.e. co-worker, relationships, supervisor relationships and emotional exhaustion) on the psychological conditions and work engagement. They found support for an indirect effect of supervisor relationships and on work engagement via psychological meaningfulness. Co-worker relationships and emotional exhaustion (inverse) indirectly affected work engagement via psychological availability. Despite the importance of the context in affecting work relationships, studies are yet to investigate the effects of aspects of job design (in addition to other relational variables) on the psychological conditions and work engagement (Kahn \& Heaphy 2014; Truss 2014).

The aims of this study were to investigate the associations among relational factors (including job design, co-worker relationships, supervisor relationships and emotional exhaustion), psychological conditions and work engagement and to test a structural model of work engagement.

\section{Literature review}

The relational model of work engagement (Kahn \& Heaphy 2014) was initially conceptualised in a study by Kahn (1990). According to the relational model, specific relational factors are linked to work engagement via three psychological conditions, namely psychological meaningfulness, psychological availability and psychological safety.

\section{Psychological conditions and work engagement}

Psychological meaningfulness refers to the level of importance something holds for an individual (Pratt \& Ashforth 2003). It relates to a person's personal appraisal of events in his or her life and the importance ascribed to these events compared to his or her personal goals, values, beliefs and identity (Matuska \& Christiansen 2008). People experience meaningfulness when they feel worthwhile, useful and valuable, knowing that they are making valuable contributions. Designing workplaces that allow people to find meaning in their work results in designing a human nature that values work (Schwartz 2015). In other words, focussing on meaningful work encourages individuals to consider meaningful work as a valuable work outcome. Individuals will engage in work contexts characterised by psychological meaningfulness (Cartwright \& Cooper 2014; Rothmann \& Buys 2011). Meaningless work often results in a lack of interest and indifference to one's work (Thomas \& Velthouse 1990). Employees who are engaged in meaningful work are not only more likely to be available in their work but also cognitively present (Steger, Dik \& Duffy 2012) and more likely to be engaged. Recent studies (Geldenhuys, Laba \& Venter 2014; May, Gilson \& Harter 2004; Rich et al. 2010; Rothmann \& Rothmann 2010) have supported the role of a meaningful work setting in experiences of psychological meaningfulness and work engagement.

Psychological availability refers to the sense of having the physical, emotional or psychological resources to engage at a particular moment' (Kahn 1990:714). It assesses one's readiness or confidence to engage in a work role, given that individuals are also engaged in many other social activities. Rothmann and Buys (2011), as well as Rothmann and Rothmann (2010), found psychological availability to be a significant predictor of work engagement.

Psychological safety is defined as 'feeling able to show and employ one's self without fear of adverse consequences to self-image, status, or career' (Kahn 1990:708). Psychological safety refers to a mutual belief that it is safe to speak up about one's failures in the workplace without suffering any interpersonal costs in the form of possible embarrassment or interpersonal threat that may impact on members' status, image or career (Edmondson 2004). Psychological safety is a key social psychological factor that enables effective learning processes, especially from previous failures (Edmondson 1999, 2004). Carmeli and Gittell (2009) draw on the concept of high-quality relationships to promote understanding of the relational underpinnings of psychological safety. Psychological safety has also been positively linked to work engagement (May et al. 2004; Olivier \& Rothmann 2007).

Although significant relations among psychological meaningfulness, availability and safety have been reported in previous studies (e.g. Rothmann \& Rothmann 2010; Rothmann \& Welsh 2013), it was not of theoretical interest to investigate the effects of these conditions on each other. Therefore, such effects are also not of interest in this study, given that they are not part of the relational model of work engagement.

\section{Effects of the relational context on psychological conditions and work engagement}

Variables in the relational context can affect individuals' psychological conditions (i.e. meaningfulness, availability and safety) and work engagement. In line with the relational model of Kahn, this study focuses on four variables, namely job design, supervisor relationships, co-worker relationships and emotional exhaustion. 
Job design shapes experiences of psychological meaningfulness and engagement through a deepened purpose (Kahn \& Heaphy 2014). A deepened purpose results from employees' meaningful contact with the beneficiaries of their work (Kahn \& Heaphy 2014). Psychological meaningfulness is likely to be experienced when individuals recognise that they are working towards a clear purpose within the organisation and when their effort is geared towards a greater social good. People want to do good, make a social contribution, serve and make a difference. Jobs that allow people to do good contribute to the engagement of employees (Grant 2007, 2008). As people attach to supervisors and the missions those supervisors embody, the purposes of their work are enlarged and made more meaningful (Kahn \& Heaphy 2014). Therefore, performing work that is regarded as important to benefit people is a vital source of psychological meaningfulness and work engagement.

Autonomy also contributes to employees' experiences of a deepened purpose (Kahn \& Heaphy 2014; May et al. 2004). Autonomy in a job relates to the degree of freedom with which employees can choose when and how to complete their tasks. It concerns the need to feel that one is in control of one's actions and that one is not being controlled (Deci \& Ryan 2000). When individuals occupy roles and perform tasks that culminate in purposes they define as important, they are more likely to experience their work as meaningful (Kahn \& Heaphy 2014). Encroachments on autonomous agency communicate to employees that they are not capable of competent decision making and block their development and maintenance of a sense that they are worthy of autonomy (Veltman 2016). In contrast, work that bears the distinctive stamp of an employee is a source of the meaningfulness found in it. The relational nature of job design elements is evident from concepts such as independence, freedom and participation. Performing work that offers opportunities for independent thought and action, freedom in carrying out work activities and participation in decisions about task completion are indicators that autonomous agency is valued.

Relationships deepen and affirm the meaningfulness of work (Kahn \& Heaphy 2014) partly through a process of social identification. Social identification provides positive confirmation of individuals' identities and provides a sense of belongingness. Therefore, supportive relationships with colleagues and supervisors (Pratt \& Ashforth 2003; Steger \& Dik 2010) shape experiences of psychological meaningfulness and work engagement through heightened belongingness (Kahn \& Heaphy 2014). Supervisors who foster a supportive work environment display concern for employees' needs and feelings provide positive feedback and encourage them to voice their concerns, develop new skills and solve workrelated problems (Deci \& Ryan 1987). Co-workers can play a fundamental role in affecting the experiences of belongingness of employees (Kahn 1990; Rosso, Dekas \& Wrzesniewski 2010; Rothmann \& Rothmann 2010).

Energising interactions as well as emotional relief and depletion affect psychological availability and work engagement (Kahn \& Heaphy 2014). Key factors that may affect psychological availability are (1) co-worker and supervisor relationships (Rothmann \& Welsh 2013) and (2) the availability of cognitive, emotional and physical resources (May et al. 2004; Rothmann \& Welsh 2013). Kahn (1990) identified depletion of emotional energy (which happens when an employee experiences emotional exhaustion) as one of the factors likely to directly affect psychological availability. Emotional exhaustion results in a loss of genuine interest in people at the interpersonal level (Schaufeli \& Buunk 2003). Many of the work characteristics that have been linked to emotional exhaustion involve contact with other people - either clients or co-workers (Leiter \& Maslach 1988). When individuals are overwhelmed, they protect themselves from the possibility of further emotional material, which diminishes their capacities to feel on behalf of themselves and others (Kahn \& Heaphy 2014).

Psychological safety ensues when the employee perceives the interpersonal relationships as characterised by mutual support, openness, trust, genuineness and flexibility (de Clercq \& Ruis 2007). Thus, relationships between supervisor and co-workers characterised by support, trust and flexibility in behavioural norms may lead to feelings of safety (May et al. 2004). Feelings of safety result in employees taking more risks that express their true selves and make them more likely to invest in their employment relationship. Furthermore, supportive co-worker relation enhances people's belief that their co-workers will be constructive in whatever criticism they may give if they fail in their efforts (Kahn 1990). Also, employees are positively affected when they perceive from their interactions that their co-workers see them as capable. Consequently, they are less likely to feel judged when they share personal views (Edmondson 2003). Psychological safety is a significant factor in increasing work engagement (Kahn 1990). On the other hand, employees will likely become stressed if they perceive their workplace as psychologically unsafe (Edmondson 2004). Previous studies (Kahn 1990; May et al. 2004; Olivier \& Rothmann 2007) have provided support for the positive relationship between coworker relationships and psychological safety as well as supervisor relationships and psychological safety.

Psychological conditions mediate between their antecedents and outcomes (Chikoko, Buitendach \& Kanengoni 2014; May et al. 2004; Rothmann \& Buys 2011). May et al. (2004) provided some empirical evidence that the psychological conditions of meaningfulness, safety and availability could mediate between engagement and its antecedents. Studies conducted in South Africa (Olivier \& Rothmann 2007) and Namibia (Rothmann \& Welsh 2013) did not support the findings concerning psychological safety by May et al. (2004). These studies did, however, show that the psychological conditions of meaningfulness and availability mediated the effects of antecedents on work engagement. Rothmann and Welsh (2013) found that a meaningful job and the availability of resources indirectly impacted on work engagement via experiences of psychological meaningfulness. Work engagement was indirectly affected via psychological availability, by the availability of resources and by co-worker 
relationships. These results provide evidence of the important role of psychological meaningfulness and psychological availability as mediators between antecedents and outcomes of engagement.

\section{Hypotheses}

Based on the review of the literature, the following hypotheses were formulated:

H1: Job design, co-worker relationships and supervisor relationships predict experiences of psychological meaningfulness.

H2: Emotional exhaustion and poor co-worker relations predict low psychological availability.

H3: Good relationships with co-workers and supervisors predict psychological safety.

H4: Psychological conditions (meaningfulness, availability and safety) predict work engagement.

H5: Antecedents of psychological conditions indirectly affect work engagement via psychological meaningfulness, availability and safety.

\section{Methods}

\section{Participants}

The data were collected using convenience sampling (Fink 2009). The research participants were made up of employees from all employment groups and educational levels within a South African agricultural organisation. The diversity of the sample (and small sample sizes) made it difficult to assess the relations among constructs in sub-samples. Moreover, given the importance of work engagement and psychological conditions for all employees, the authors wanted to test relations in the diverse sample. The participants with the lowest educational level had an adequate literacy level to complete the questionnaire. The demographic composition of the participants is provided in Table 1.

Table 1 indicates that approximately half of the participants, namely 221 (49.9\%), were male participants. A total of 37.2\% were Afrikaans speaking, 16.5\% were between 31 and 35 years of age and $19.4 \%$ had a Master's degree.

\section{Measuring instruments}

A questionnaire was developed to gather information on demographic characteristics of the participants.

Four scales that represent relational factors in individuals' jobs, that is, job design, co-worker relationships, supervisor relationships and emotional exhaustion (May et al. 2004), were administered. Job design was measured using four items $(\rho=0.80)$, for example, 'Do you think you are doing important work people can benefit from?' Co-worker relationships were measured using two items $(\rho=0.80)$, for example, 'Can you ask your colleagues for help if necessary?' Supervisor relationships were measured using three items ( $\rho=0.84$ ), for example, 'Do you get on well with your supervisor?' Emotional exhaustion was measured using three items $(\rho=0.80)$ taken from the Burnout Scale (Asiwe, Jorgensen \& Hill 2014), for example, 'I lack the energy to build relationships with people'.

An adapted version of the Psychological Conditions Questionnaire of May et al. (2004) was used to measure the psychological conditions of meaningfulness, safety and availability. Psychological meaningfulness was measured using four items $(\rho=0.90)$, for example, 'The work I do on this job is meaningful to me'. Psychological safety was measured using a scale developed by Asiwe (2014). It consists of five items $(\rho=0.80)$, for example, 'There is a threatening environment at my workplace'. Psychological availability was measured using five items ( $\rho=0.88)$, for example, 'I am confident in my ability to handle competing demands at work'.

Engagement was measured using a seven-item Work Engagement Scale (WES; Asiwe 2014). The WES measured three components of engagement based on Kahn's conceptualisation and the extension of the theory by May et al. (2004): physical engagement (two items), emotional engagement (two items) and cognitive engagement (three items). Examples of items are as follows: 'I am full of energy while working' (physical enagement), 'I am emotionally connected to my job' (emotional engagement) and 'I am not distracted while doing my job' (cognitive engagement). All the items used in this study were scored on a seven-point Likert scale ranging from 1 (never) to 7 (always). The reliability of the scale was acceptable $(\rho=0.84)$.

\begin{tabular}{|c|c|c|c|}
\hline Item & Category & Frequency & $\%$ \\
\hline \multirow[t]{3}{*}{ Gender } & Male & 221 & 49.9 \\
\hline & Female & 217 & 49.0 \\
\hline & Missing cases & 5 & 1.1 \\
\hline \multirow[t]{9}{*}{ Age } & $20-25$ & 28 & 6.3 \\
\hline & $26-30$ & 53 & 12.0 \\
\hline & $31-35$ & 73 & 16.5 \\
\hline & $36-40$ & 60 & 13.5 \\
\hline & $41-45$ & 72 & 16.3 \\
\hline & $46-50$ & 71 & 16.0 \\
\hline & $51-55$ & 37 & 8.4 \\
\hline & $>55$ & 44 & 9.9 \\
\hline & Missing cases & 5 & 1.1 \\
\hline \multirow[t]{9}{*}{ Education } & Grade 9-11 & 59 & 13.3 \\
\hline & Grade 12 & 60 & 13.5 \\
\hline & Certificate/Diploma & 70 & 15.8 \\
\hline & Bachelor's degree & 44 & 9.9 \\
\hline & Honours degree & 42 & 9.5 \\
\hline & Master's degree & 86 & 19.4 \\
\hline & $\mathrm{PhD}$ & 51 & 11.5 \\
\hline & Other & 24 & 5.4 \\
\hline & Missing cases & 7 & 1.6 \\
\hline \multirow[t]{6}{*}{ Position } & Research assistant & 124 & 28.0 \\
\hline & Research technician & 122 & 27.5 \\
\hline & Researcher & 110 & 24.8 \\
\hline & $\begin{array}{l}\text { Programme manager/ } \\
\text { Specialist scientist }\end{array}$ & 17 & 3.8 \\
\hline & Support staff & 62 & 14.0 \\
\hline & Missing cases & 8 & 1.8 \\
\hline
\end{tabular}




\section{Research procedure and ethical considerations}

The researcher obtained written permission to conduct the research from the director of human resources of the organisation. Subsequently, a letter that explained the aim of the study was emailed to employees within the organisation, requesting their participation in the survey and emphasising the confidentiality of the research study. The participants who indicated their readiness to take part in the study were personally provided with a consent form and paper-andpencil questionnaires that were completed within a 6-week period. Items were selected to fit the aim of the study. However, the results of factor analyses in a broader study by Asiwe (2014) were also considered. A total of 472 questionnaires (indicating a $92 \%$ response rate) were returned. However, only 443 questionnaires were considered suitably completed and were used for the statistical analysis. Data were captured in an SPSS data file for use in Mplus 7.31.

\section{Statistical analysis}

The analysis of the data was carried out using Mplus version 7.31 (Muthén \& Muthén 1998-2014). Items of the questionnaires were defined as continuous, and the maximum likelihood parameter estimates (MLR) with standard errors were used as estimators. The MLR estimator provides standard errors and $\chi^{2}$ test statistics that are robust to non-normality (Wang \& Wang 2012). The Akaike Information Criterion (AIC) and Bayes Information Criterion (BIC) were used to compare structural models. The AIC, a comparative measure of fit, is meaningful when one estimates different models. The BIC provides an indication of model parsimony (Kline 2016). The lowest AIC and BIC values indicate the best fitting model. Point estimate reliabilities ( $\rho$ ) of scales were computed using a formula based on the sum of squares of standardised loadings and the sum of standardised variance of error terms (Wang \& Wang 2012). Point estimate reliabilities higher than 0.70 are regarded as acceptable.

The $\chi^{2}$ statistic is usually examined to test for overall model fit (Hooper, Coughlan \& Mullen 2008). However, it is necessary to consider other fit indices in addition to $\chi^{2}$ because of some limitations in its use. These include sensitivity to sample size (the statistic most often rejects a model when a large sample is used) and to multivariate normality (Hooper et al. 2008). Therefore, the following fit indexes, produced by Mplus, were used in this study: the Root Mean Square Error of Approximation (RMSEA), the Comparative Fit Index (CFI) and the Tucker-Lewis Index (TLI). For the CFI and TLI, a value of 0.90 and above indicates an acceptable fit (Bentler 1992; Schumacker \& Lomax 1996). According to Cudeck and Browne (1993), there is a good model fit if the RMSEA value is less than or equal to 0.05 . Values up to 0.08 indicate reasonable fit (Cudeck \& Browne 1993) while values above 0.10 indicate a poor fit (MacCallum, Browne \& Sugawara 1996). The indirect model function of Mplus was used with the bootstrapping resampling option enabled and set to 10000 samples (Shrout \& Bolger 2002).
We used Cohen's (1988) guidelines to assess the practical significance correlations and the percentage of variance explained $\left(R^{2}\right)$ by regression equations. The following guidelines indicate the practical significance of correlations: $r<0.30$ - small effect, $r>0.30$ - medium effect and $r>0.50-$ large effect. The following guidelines indicate the practical significance of $R^{2}$ : $<0.09$ - small effect, 0.09 - medium effect and 0.25 - large effect.

\section{Results}

In the next subsection, the results are reported. First, the results of the test of the measurement model are reported, followed by the results of the tests of the alternative structural models.

\section{Testing the measurement model}

First, confirmatory factor analysis was used to test a hypothesised measurement model, to investigate whether individual measurement items loaded significantly onto the scales with which they were associated. The measurement model consisted of eight latent variables, namely: (1) Job design (measured by means of four observed variables); (2) Coworker relationships (measured by means of two observed variables; (3) Supervisor-worker relationships (measured by means of three observed variables; (4) Emotional exhaustion (measured by means of three observed variables); (5) Work engagement (measured by means of seven observed variables); (6) Psychological meaningfulness (measured by means of four observed variables); (7) Psychological safety (measured by means of five observed variables); and (8) Psychological availability (measured by means of five observed variables). A $\chi^{2}$ value of $677.95(d f=467)$ was obtained for the hypothesised measurement model. Acceptable fit statistics were found for the four fit indices: TLI $=0.95$, CFI 0.95 and RMSEA $=0.03$ [90\% confidence interval $(\mathrm{CI})=0.03-0.04$, probability RMSEA $<0.05=1.00]$, SRMR $=0.05$.

\section{Descriptive statistics, reliabilities and correlations}

Table 2 depicts the descriptive statistics, reliabilities and correlations of the latent variables.

Table 2 reveals a negative correlation between work engagement and emotional exhaustion (practically significant, medium effect). Work engagement correlated positively with job design, co-worker relationships, supervisor relationships and psychological availability (all medium effects), as well as psychological meaningfulness (large effect). Psychological meaningfulness correlated positively with psychological availability (large effect), job design and supervisor relationships (both medium effects) and negatively with emotional exhaustion (medium effect). Psychological availability correlated positively with job design (large effect) and supervisor relationships (medium effect) and negatively with emotional exhaustion (negative effect). Psychological safety correlated positively with job design and supervisor relationships (both medium effects) and negatively with 
TABLE 2: Descriptive statistics, reliability $(\rho)$ and correlation matrix of the latent variables.

\begin{tabular}{|c|c|c|c|c|c|c|c|c|c|c|}
\hline Variable & Mean (scale: 1-7) & SD & $\rho$ & 1 & 2 & 3 & 4 & 5 & 6 & 7 \\
\hline 1. Work engagement & 5.75 & 0.89 & 0.84 & - & - & - & - & - & - & - \\
\hline 2. Psychological meaningfulness & 6.00 & 0.90 & 0.90 & $0.52 *+$ & - & - & - & - & - & - \\
\hline 3. Psychological availability & 5.80 & 0.96 & 0.88 & $0.49 * \dagger$ & $0.54 * \div$ & - & - & - & - & - \\
\hline 4. Psychological safety & 4.73 & 1.30 & 0.80 & 0.12 & 0.11 & $0.25 *$ & - & - & - & - \\
\hline 5. Job design & 5.61 & 1.10 & 0.80 & $0.40 * \dagger$ & $0.49 * \dagger$ & $0.55 * \dagger$ & $0.33 * \dagger$ & - & - & - \\
\hline 6. Co-worker relationships & 5.45 & 1.28 & 0.80 & $0.30 * \dagger$ & $0.25 *$ & $0.15^{*}$ & $0.21 *$ & $0.21 *$ & - & - \\
\hline 7. Supervisor relationships & 5.76 & 1.18 & 0.84 & $0.43 * \dagger$ & $0.34 * \dagger$ & $0.41 * \dagger$ & $0.33^{* \dagger} \dagger$ & $0.47 * \dagger$ & $0.54 * \ddagger$ & - \\
\hline 8. Emotional exhaustion & 2.27 & 1.06 & 0.80 & $-0.48 * \dagger$ & $-0.24^{*}$ & $-0.32 * \dagger$ & $-0.36 * \dagger$ & $-0.28 *$ & $-0.14 *$ & $-0.27 *$ \\
\hline
\end{tabular}

$*, p \leq 0.01$.

$\dagger, r>0.30$ (practically significant, medium effect); $\star, r>0.50$ (practically significant, large effect).

TABLE 3: Fit indices and standardised path coefficients of the structural models.

\begin{tabular}{|c|c|c|c|c|}
\hline Measures & Variable & $\begin{array}{l}\text { Direct and indirect effects } \\
\text { (Model 1) }\end{array}$ & $\begin{array}{l}\text { Indirect effects } \\
\text { (Model 2) }\end{array}$ & $\begin{array}{l}\text { Direct effects } \\
\text { (Model 3) }\end{array}$ \\
\hline \multirow[t]{8}{*}{ Fit indices } & $\chi^{2}$ & $775.22 * *$ & $825.97 * *$ & $872.67^{* *}$ \\
\hline & $d f$ & 472 & 476 & 479 \\
\hline & CFI & 0.93 & 0.92 & 0.91 \\
\hline & RMSEA & 0.04 & 0.04 & 0.04 \\
\hline & RMSEA $90 \% \mathrm{Cl}$ & {$[0.03,0.04]$} & {$[0.04,0.05]$} & {$[0.04,0.05]$} \\
\hline & SRMR & 0.08 & 0.09 & 0.13 \\
\hline & AIC & 43051.25 & 43112.37 & 43170.85 \\
\hline & $\mathrm{BIC}$ & 43550.66 & 43595.41 & 43641.61 \\
\hline \multirow[t]{3}{*}{ Direct effects on psychological meaningfulness } & Job design & $0.31 * *$ & $0.32 * *$ & - \\
\hline & Supervisor relationships & 0.07 & 0.08 & - \\
\hline & Co-worker relationships & 0.16 & 0.16 & - \\
\hline Direct effects on psychological availability & Emotional exhaustion & $-0.26 * *$ & $-0.27^{* *}$ & - \\
\hline \multirow[t]{2}{*}{ Direct effects on psychological safety } & Supervisor relationships & $0.49 * *$ & $0.51 * *$ & - \\
\hline & Co-worker relationships & -0.11 & -0.11 & - \\
\hline \multirow[t]{6}{*}{ Direct effects on work engagement } & Job design & 0.06 & - & 0.08 \\
\hline & Supervisor relationships & 0.13 & - & $0.20 *$ \\
\hline & Co-worker relationships & 0.07 & - & 0.06 \\
\hline & Emotional exhaustion & $-0.35 * *$ & - & $-0.35 * *$ \\
\hline & Psychological meaningfulness & $0.27 * *$ & $0.36 * *$ & $0.28 * *$ \\
\hline & Psychological availability & $0.15 *$ & $0.31 * *$ & $0.15^{*}$ \\
\hline
\end{tabular}

$d f$, degrees of freedom; TLI, Tucker-Lewis Index; CFI, Comparative Fit Index; RMSEA, Root Mean Square Error of Approximation; Cl, confidence interval; SRMR, Standardised Root Mean Square Residual; AIC, Akaike Information Criterion; BIC, Bayes Information Criterion.

$*, p<0.05 ; * *, p \leq 0.01$.

emotional exhaustion. Regarding the relational variables, job design was positively associated with supervisor relationships (medium effect). Co-worker relationships were positively related to supervisor relationships (large effect).

\section{Testing the structural model}

The structural model was tested based on the measurement model. Three competing models were tested because of the cross-sectional nature of the data. The hypothesised relationships were tested using latent variable modelling as implemented by Mplus 7.31 (Muthén \& Muthén 1998-2014). Direct and indirect effects were tested in Model 1; only indirect effects were tested in Model 2, while only direct effects were tested in Model 3. Table 3 shows the fit indices and standardised path coefficients estimated by Mplus for the three models. Results indicated a fair fit of the hypothesised model (i.e. the direct and indirect effects model) to the data: $\chi^{2}(d f=472)=775.22 ; p=0.000 ; \mathrm{CFI}=0.93, \mathrm{TLI}=$ 0.93, RMSEA $=0.04(90 \%$ CI 0.03-0.04), $\mathrm{SRMR}=0.07, \mathrm{AIC}=$ 43051.25 and $\mathrm{BIC}=43550.66$.
Next, the obtained relationships of the final structural model are discussed regarding the hypotheses of this study (see Model 1 in Table 3 and Figure 1).

For the portion of the model predicting psychological meaningfulness, the path coefficient of job design $(\beta=0.31$, $p<0.001$ ) was statistically significant and positive, while the path coefficients of supervisor relationships and co-worker relationships were not statistically significant. The MLRestimated equation accounted for a moderate proportion of the variance in psychological meaningfulness $\left(R^{2}=0.18\right)$. These results provide partial support for Hypothesis 1.

Concerning the portion of the model predicting psychological availability, the path coefficient of co-worker relationships was statistically significant and positive $(\beta=0.20, p<0.01)$, while the path coefficient of emotional exhaustion was statistically significant and negative $(\beta=-0.26, p<0.01)$. A moderate proportion of the variance in psychological availability $\left(R^{2}=0.12\right)$ was accounted for by the regression equation. These results provide support for Hypothesis 2. 


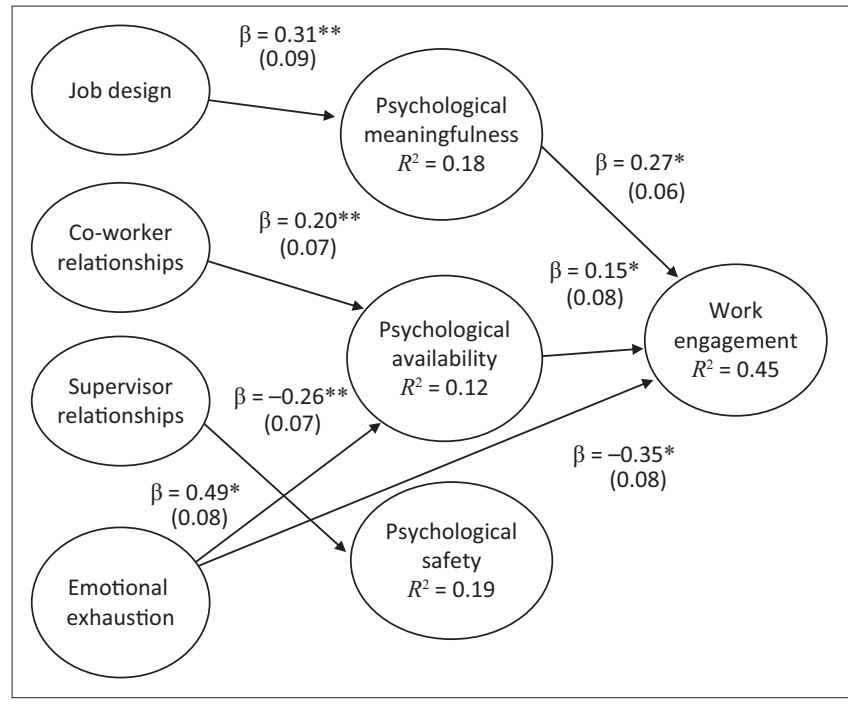

$*, p<0.05 ; * *, p<0.01$.

FIGURE 1: The final structural model.

Regarding the part of the model predicting psychological safety, the path coefficient of supervisor relationships was statistically significant and positive $(\beta=0.49, p<0.01)$, while the path coefficient of co-worker relationships was not statistically significant. A moderate proportion of the variance in psychological safety $\left(R^{2}=0.19\right)$ was accounted for by good supervisor relationships. These results provide partial support for Hypothesis 3.

With regard to the part of the model predicting work engagement, the path coefficients of emotional exhaustion ( $\beta=-0.35, p<0.001)$, psychological meaningfulness $(\beta=0.27$, $p<0.01)$ and psychological availability $(\beta=0.15, p<0.05)$ were statistically significant and had the expected signs. The path coefficients of co-worker relationships, supervisor relationships and job design, were not statistically significant. A large proportion of the variance in work engagement was accounted for by the structural model $\left(R^{2}=0.45\right)$. These results provide partial support for Hypothesis 4 .

\section{Indirect effects}

The procedure explained by Hayes (2009) was used to determine whether the relations between job design, co-worker and supervisor relationships, meaningful work, and emotional exhaustion and work engagement were affected by psychological conditions of availability, meaningfulness and safety. Bootstrapping (10 000 samples) was used to construct two-sided bias-corrected $95 \%$ CIs to assess indirect effects. Job design had a significant indirect effect on work engagement: the 95\% CIs of job design via psychological meaningfulness did not include zero. Job design had indirect effects on work engagement via psychological meaningfulness $(\beta=0.09, p<0.01 ; 95 \% \mathrm{CI}=$ $0.03-0.17)$. No other significant indirect effects were found. This result provides partial support for Hypothesis 5.

\section{Discussion}

The aims of this study were to investigate the associations among relational factors (job design, co-worker relationships, supervisor relationships and emotional exhaustion), psychological conditions and work engagement and to test a structural model of work engagement. The results showed that psychological meaningfulness and psychological availability had positive effects on work engagement, while emotional exhaustion had a negative effect on work engagement. Relational aspects of job design had a positive indirect effect on work engagement (via psychological meaningfulness). Emotional exhaustion had a negative effect on psychological availability, while co-worker relationships had a positive effect on psychological availability. Supervisor relationships contributed to psychological safety.

As predicted by the relational model (Kahn \& Heaphy 2014), work engagement was statistically significantly and positively associated with psychological meaningfulness. Recent studies (Janik \& Rothmann 2016; May et al. 2004; Olivier \& Rothmann 2007; Rothmann \& Rothmann 2010; Rothmann \& Welsh 2013) showed that psychological meaningfulness predicts work engagement. Our results confirm the findings of Janik and Rothmann (2016) that psychological meaningfulness was the most important psychological condition that contributes to work engagement. Psychological meaningfulness is characterised by the feeling that one is making a difference, resulting in the ability to give yourself to others and your work (Kahn \& Heaphy 2014).

Psychological availability (i.e. individuals' confidence in their abilities to handle demands, think clearly, and display appropriate emotions) contributed to work engagement. Kahn and Heaphy (2014) pointed out that psychological availability reflects one's readiness or confidence to engage in a work role, given that individuals are also engaged in other activities. Previous studies (e.g. Rothmann \& Buys 2011; Rothmann \& Rothmann 2010) also showed that psychological availability is significantly associated with work engagement. However, this study showed that the effect of psychological meaningfulness compared to psychological availability on work engagement was almost twice as strong.

In addition to the positive effects of psychological meaningfulness and psychological availability, emotional exhaustion had a negative effect on work engagement in the structural model. Based on the relational model (Kahn \& Heaphy 2014), and the findings of a recent study (Janik \& Rothmann 2016), we hypothesised that psychological availability would mediate the relation between emotional exhaustion (caused by energy depletion) and work engagement. Although we found that emotional exhaustion had a direct negative effect on psychological availability, it affected work engagement directly and negatively rather than indirectly via psychological availability. The negative relation between emotional exhaustion and psychological availability was expected: individuals whose emotional resources are not depleted will make themselves available psychologically to engage in relationships and work.

The results support the importance and usefulness of relational variables in understanding individuals' experiences 
of psychological conditions and work engagement (Kahn \& Heaphy 2014). In the structural model, job design predicted psychological meaningfulness and also work engagement via psychological meaningfulness. Relational aspects of job design aspects include perceiving one's job as something important which can benefit people, opportunities for independent thought and action, freedom in carrying out work activities and participating in decision making. In line with the relational model (Kahn \& Heaphy 2014) and research findings of Grant (2007, 2008), individuals contact with beneficiaries (regarded as part of job design in this study) allows them to deepen the meaning and purpose of their work. Furthermore, by allowing freedom, independence and participation in decision making, employees are encouraged to put their unique stamps on their work, which support their autonomous agency and deepen their purpose at work (Veltman 2016).

Based on the relational model of work engagement, we expected that relationships with supervisors and coworkers would predict psychological safety. While both sound supervisor and co-worker relationships were positively related to psychological safety, the structural model showed that (only) supervisor relationships had a strong and significant effect on people's feelings of psychological safety. The results showed a strong relation between supervisor and co-worker relationships, which might suggest that co-worker relationships tend to be good when supervisor relationships were good. Concerning emotional exhaustion, psychological safety is threatened when employees feel overwhelmed, and they protect themselves from the possibility of further sensitive material (Kahn \& Heaphy 2014).

\section{Limitations}

This study had various limitations. First, the use of a crosssectional survey design does not allow claims of causality of relationships because the findings of the study were based on correlational data. Second, we used non-probability sampling, which means that it is not possible to generalise findings. Third, we did not assess the measurement invariance of the relational model for different groups (e.g. job levels and cultural groups) in the organisation.

\section{Conclusion}

\section{Recommendations}

Investing in human resource management policies aimed at ensuring proper job design, good relationships with coworkers and supervisors and reducing emotional exhaustion are recommended for agricultural research organisations as this could ensure greater psychological meaningfulness, availability and safety and engagement of employees. Organisations should provide a work environment that enhances meaningfulness and availability and reduces emotional exhaustion of workers to improve their engagement. Future research should investigate the relational model of work engagement in different demographic groups using larger samples and a longitudinal design. This could provide more insight into the effects of job design, co-worker relationships, supervisor relationships and emotional exhaustion on the psychological conditions and work engagement of employees at work.

\section{Acknowledgements}

All the authors contributed equally. Funding was made available by the National Research Foundation.

\section{Competing interests}

The authors declare that they have no financial or personal relationships that may have inappropriately influenced them in writing this article.

\section{Authors' contributions}

All the authors contributed equally.

\section{References}

Asiwe, D.N., 2014, 'The well-being of employees in a South African agricultural research organisation', Unpublished thesis, North-West University, South Africa.

Asiwe, D.N., Jorgensen, L.I. \& Hill, C., 2014, 'The development and investigation of the psychometric properties of a burnout scale within a South African agricultural research institution', SA Journal of Industrial Psychology 40(1), Art. \#1194, 1-14. https://doi.org/10.4102/sajip.v40i1.1194

Bakker, A.B. \& Demerouti, E., 2007, 'The job demands-resources model: State of the art', Journal of Managerial Psychology 22, 309-328. https://doi. org/10.1108/02683940710733115

Bakker, A.B. \& Demerouti, E., 2008, 'Towards a model of work engagement', Career Development International 13, 209-223. https://doi.org/10.1108/ 13620430810870476

Bakker, A.B. \& Leiter, M.P., 2010, Work engagement: A handbook of essential theory and research, Psychology Press, New York.

Bentler, P.M., 1992, 'On the fit of models to covariances and methodology to the bulletin', Psychological Bulletin 112, 400-404. https://doi.org/10.1037/00332909.112.3.400

Carmeli, A. \& Gittell, J.H., 2009, 'High-quality relationships, psychological safety, and learning from failures in work organizations', Journal of Organizational Behavior 30(6), 709-729. https://doi.org/10.1002/job.565

Cartwright, S. \& Cooper, C.L., 2014, 'Towards organizational health: Stress, positive organizational behavior, and employee well-being', in G.F. Bauer \& O. Hamming (eds.), Bridging occupational, organizational and public health, pp. 29-42, (eds.), Bridging occupational, organ
Springer, Dordrecht, The Netherlands.

Chikoko, G.L., Buitendach, J.H. \& Kanengoni, H., 2014, 'The psychological conditions that predict work engagement among tertiary education employees', Journal of Psychology in Africa 24(6), 469-474.

Cohen, J., 1988, Statistical power analysis for the behavioral sciences, 2nd edn. Lawrence Erlbaum Associates, Hillsdale, NJ.

Cudeck, R. \& Browne, M.W., 1993, 'Alternative ways of assessing model fit', in K.A. Bollen \& J. Scott Long (eds.), Testing structural equation models, pp. 136-162, Sage, Newbury Park, CA.

Deci, E.L. \& Ryan, R.M., 1987, 'The support of autonomy and the control of behavior', Journal of Personality and Social Psychology 53, 1024-1037. https://doi. org/10.1037/0022-3514.53.6.1024

Deci, E.L. \& Ryan, R.M., 2000, 'The "what" and "why" of goal pursuits: Human needs and the self-determination of behavior', Psychological Inquiry 11, 319-338. https://doi.org/10.1207/S15327965PLI1104_01

De Clercq, D. \& Ruis, I.B., 2007, 'Organizational commitment in Mexican small and medium-sized firms: The role of work status, organizational climate, and entrepreneurial orientation', Journal of Small Business Management 45, 467-490.

Edmondson, A., 1999, 'Psychological safety and learning behaviour in work teams', Administrative Science Quarterly 44, 350-383. https://doi.org/10.2307/2666999

Edmondson, A.C., 2003, 'Speaking up in the operating room: How team leaders promote learning in interdisciplinary action teams', Journal of Management Studies 40, 1419-1452. https://doi.org/10.1111/1467-6486.00386

Edmondson, A.C., 2004, 'Psychological safety, trust and learning in organizations: A group-level lens', in R.M. Kramer \& K.S. Cook (eds.), Trust and distrust in organizations: Dilemmas and approaches, pp. 239-271, New York: Russel Sage Foundation.

Fink, A., 2009, How to conduct surveys: A step by-step guide, 4th edn., Sage, Thousand Oaks, CA. 
Geldenhuys, M., Laba, K. \& Venter, C.M., 2014, 'Meaningful work, work engagement and organisational commitment', SA Journal of Industrial Psychology 40(1), 1-10. https://doi.org/10.4102/sajip.v40i1.1098

Grant, A.M., 2007, 'Relational job design and motivation to make a prosocial difference', Academy of Management Review 32, 393-417. https://doi. org/10.5465/AMR.2007.24351328

Grant, A.M., 2008, 'Designing jobs to be good: Dimensions and psychological consequences of prosocial job characteristics', The Journal of Positive Psychology 3, 19-39. https://doi.org/10.1080/17439760701751012

Hayes, A.F., 2009, 'Beyond Baron and Kenny: Statistical mediation analysis in the new millennium', Communication Monographs 76, 408-420. https://doi. org/10.1080/03637750903310360

Hooper, D., Coughlan, J. \& Mullen, M., 2008, 'Structural equation modelling: Guidelines for determining model fit', Electronic Journal of Business Research Methods 6, 53-60.

Janik, M. \& Rothmann, S., 2016, 'Work engagement of secondary school educators in Namibia: The effects of the relational context and psychological conditions', Namibia: The effects of the relational context
Journal of Psychology in Africa 26(4), 316-325.

Kahn, W.A., 1990, 'Psychological conditions of personal engagement and disengagement at work', Academy of Management Journal 33, 692-724. https:// doi.org/10.2307/256287

Kahn, W.A. \& Heaphy, E.D., 2014, 'Relational context of personal engagement at work', in C. Truss, R. Delbridge, K. Alfes, A. Shantz \& E. Soane (eds.), Employee engagement in theory and practice, pp. 82-96, Routledge, New York.

Kline, R.B., 2016, Principles and practice of structural equation modelling, The Guilford Press, New York.

Leiter, M.P. \& Maslach, C., 1988, 'The impact of interpersonal environment on burnout and organizational commitment', Journal of Organizational Behavior 9, 297-308. https://doi.org/10.1002/job.4030090402

Maccallum, R.C., Browne, M.W. \& Sugawara, H.M., 1996, 'Power analysis and determination of sample size for covariance structure modelling', Psychological Methods 1, 130-149. https://doi.org/10.1037/1082-989X.1.2.130'

Matuska, K.M. \& Christiansen, C.H., 2008, 'A proposed model of lifestyle balance', Journal of Occupational Science 15, 9-19. https://doi.org/10.1080/14427591.200 8.9686602

May, D.R., Gilson, R.L. \& Harter, L.M., 2004, 'The psychological conditions of meaningfulness, safety and availability and the engagement of the human spirit at work', Journal of Occupational and Organizational Psychology 77, 11-37. https:// doi.org/10.1348/096317904322915892

Muthén, L.K. \& Muthén, B.O., 1998-2014, Mplus user's guide, 7th edn., Muthén \& Muthén, Los Angeles, LA.

Olivier, A.L. \& Rothmann, S., 2007, 'Antecedents and consequences of work engagement in a multinational oil company', SA Journal of Industrial Psychology 33(3), 49-56. https://doi.org/10.4102/sajip.v33i3.396

Pratt, M.G. \& Ashforth, B.E., 2003, 'Fostering positive meaning at work', in K.S Cameron, J.E. Dutton \& R.E. Quinn (eds.), Positive organizational scholarship: Foundations of a new discipline, pp. 309-327, Berrett-Koehler Publishers, San Francisco, CA.

Rich, B.L., Lepine, J.A. \& Crawford, E.R., 2010, 'Job engagement: Antecedents and effects on job performance', Academy of Management Journal 53, 617-635. https://doi.org/10.5465/AMJ.2010.51468988
Rosso, B.D., Dekas, K.H. \& Wrzesniewski, A., 2010, 'On the meaning of work: A theoretical integration and review', Research in Organizational Behavior 30, 91-127. https://doi.org/10.1016/j.riob.2010.09.001

Rothbard, N.P. \& Patil, S.V., 2012, 'Being there: Work engagement and positive organizational scholarship', in K.S. Cameron \& G.M. Spreitzer (eds.), The Oxford handbook of positive organizational scholarship, pp. 56-68, Oxford University Press, New York.

Rothmann, S., 2017, 'Employee engagement', in L. G. Oades, M. Steger, A. Delle-Fave \& Passmore, J. (eds.), The Wiley-Blackwell handbook of the psychology of positivity and strengths-based approaches at work, pp. 317-341, Wiley, Chichester.

Rothmann, S. \& Buys, C., 2011, 'Job demands and resources, psychological conditions, religious coping and work engagement of reformed church ministers', Journal of Psychology in Africa 21(2), 173-185.

Rothmann, S. \& Rothmann, S., Jr., 2010, 'Factors associated with employee engagement in South Africa', SA Journal of Industrial Psychology/SA Tydskrif vir Bedryfsielkunde 36(2), Art. \#925, 1-12. https://doi.org/10.4102/sajip.v36i2.925

Rothmann, S. \& Welsh, C., 2013, 'Employee engagement: The role of psychological conditions', Management Dynamics: Journal of the Southern African Institute for Management Scientists 22(1), 14-25.

Saks, A.M., 2006, 'Antecedents and consequences of employee engagement', Journa of Managerial Psychology 21(7), 600-619. https://doi.org/10.1108/026839 40610690169

Schaufeli, W.B. \& Bakker, A.B., 2004, 'Job demands, job resources and their relationship with burnout and engagement: A multi-sample study', Journal of Organizational Behavior 25, 293-315. https://doi.org/10.1002/job.248

Schaufeli, W.B. \& Buunk, B.P., 2003, 'Burnout: An overview of 25 years of research and theorizing', in M.J. Schabracq, J.A.M. Winnubst \& C.L. Cooper (eds.), The handbook of work and health psychology, pp. 383-425, John Wiley \& Sons, London.

Schumacker, R.E. \& Lomax, R.G., 1996, A beginner's guide to structural equation modelling, Erlbaum, Hillsdale, NJ.

Schwartz, B., 2015, Why we work? Simon and Schuster, London.

Shrout, P.E. \& Bolger, N., 2002, 'Mediation in experimental and nonexperimental studies: New procedures and recommendations', Psychological Methods 7, 422-445. https://doi.org/10.1037/1082-989X.7.4.422

Steger, M.F. \& Dik, B.J., 2010, 'Work as meaning: Individual and organizational benefits of engaging in meaningful work', in P.A. Linley, S. Harrington \& N. Garcea (eds.), Oxford handbook of positive psychology and work, pp. 131-142, Oxford University Press, Oxford.

Steger, M.F., Dik, B.J. \& Duffy, R.D., 2012, 'Measuring meaningful work: The Work and Meaning Inventory (WAMI)', Journal of Career Assessment 20, 322-337. https:// doi.org/10.1177/1069072711436160

Thomas, K.W. \& Velthouse, B.A., 1990, 'Cognitive elements of empowerment: An "interpretive" model of intrinsic task motivation', Academy of Management Review 15(4), 666-681.

Truss, K., 2014, The future of research in employee engagement, viewed 05 March 2017, from http://www.engageforsuccess.org/wp-content/uploads/2014/03/ Katie-Truss.pdf

Veltman, A., 2016, Meaningful work, Oxford University Press, New York.

Wang, J. \& Wang, X., 2012, Structural equation modeling: Applications using Mplus, Wiley, Chichester. 